\title{
Assessment of Lighting Design of Restaurants with Reference to its Aesthetics and Function
}

\author{
Sadia Farooq ${ }^{1}$, Aqib Ahmed², Mohammad Arif Kamal, \\ ${ }^{1}$ Department of Family and Consumer Sciences, University of Home Economics, Lahore, Pakistan \\ ${ }^{2}$ AA Studio, 17 Goodmayes, London, United Kingdom \\ ${ }^{3}$ Architecture Section, Aligarh Muslim University, Aligarh-202002, India
}

Received June 29, 2020; Revised July 20, 2020; Accepted August 28, 2020

Copyright $\mathrm{C} 2020$ by authors, all rights reserved. Authors agree that this article remains permanently open access under the terms of the Creative Commons Attribution License 4.0 International License

\begin{abstract}
The Restaurants are purposefully designed not only to dine in but also for recreation and satisfaction. The study is an assessment of lighting in restaurant qualitatively, based on observations and interviews. The lighting, in a restaurant named 'Premier Family Dining', is observed and interviews were conducted with the restaurateur, restaurant manager, and several regular diners In this paper, the lighting design of restaurants with reference to its aesthetics and function has been studied. The research shows that the lighting of the restaurant is used excessively for aesthetical purposes such as light coming from the ceiling, walls, pillars and floors, but with no control of voltage or intensity of light. Excessive use of light increases the expenses on electricity and creates blurriness. The lighting design needs a few alterations to bring the restaurant up to date and more functional than it is. These alterations did not require much of finance but they would bring a blooming change in the interiors of the restaurant.
\end{abstract}

Keywords Lighting Design, Interiors, Restaurants, Aesthetics, Function, Lahore

\section{Introduction}

The restaurant is a commercial place, it requires a pleasant, public, spacious, relaxed, and visually clear environment. The required environment can be achieved through the design of the building, materials used in construction and finishes, and also the arrangement of furnishings. But the most important elements are the lights and color which play a vital role in the life of a building and these two things give sensibility to the environment. Some buildings, like offices, are concerned with the objective to have energy-efficient rooms to reduce expenses, and many buildings such as restaurants may be concerned with the more aesthetics through lighting to their customers [1],[2]. The important is to use light both as science and art in a setting such as if a light circuit is made with scientific knowledge and rules then the light color and appearance may be changed through its color and intensity [3], [4]. The reason to apply different lighting designs in the restaurants is that the people come in a restaurant not only for food to eat but they also want to enjoy the ambiance and want to remember because of its unique style [5].

A restaurant is also expected to be aesthetical from the interior and exterior in view of the customers. The beauty of a place impacts highly on the performance and output but it is also optional. The functionality is considered more than aesthetics but both work better together as compared to single [6]. Restaurants are the spaces that can impact on perceptions of their patrons and can arouse their emotional stability. Such places can be accomplished with facilities, and functionality but a factor of wow can be created with aesthetical ambience, spatial layout, windows, etc. [7],[8]. When an interior designer organizes a place according to the elements of design, the importance should be given not only to door, windows, walls, and ceilings, but to the finishing to hold on the customers for a long duration. The light and color are the most influencing factors in the way to apply aesthetics. The color and light have a wide variety and for choosing them requires the understanding of the preferences, culture and trends of people who would enjoy by coming to a place [1],[9]. There is a chain of restaurants in Pakistan which opened in the last decade and expanded very well. Most of them are the foreign franchise such as fast-food restaurants or Pakistani which are well known for their hospitality and good taste and somehow keenness of people to dine out [10]. Even in Lahore more than seventy formal, well-established restaurants are working other than those are street shops for cooked foods, burger and BBQ shops, caterers and small hangout places for food are also 
numerous. That is all a commercial set up which is growing fast and the owners of them are investing a lot in this field but the proper and accurate guidance is required and this paper will be an addition in the right direction.

\section{Background and Literature Review}

The light and color are very basic perceptions a person receives about an environment that makes him comfortable or uncomfortable to stay there [11]. The developers are interested in beautifying things through light and color in the interior. The requirement is to have the technical knowledge, advancement in color mixing, and updating due to new technologies in the lighting area called the lighting science. The important is not the technology but the implementation for whom and who is the human. So, the light and color are being designed for the human who needs it to be in good quality for a healthy and safe world around him. Ultimately, light and color are about meeting the individual's needs so when people see well ultimately, they will feel better.

Light is life as we can feel happy in bright light, also because of appropriate light present in a place whether it is coming from the window or lit in a bulb. It can complete a situation to make it depressing or enjoyable [12]. An efficient and functional light and color strategy can provide proper levels of illumination and reduce energy costs. The research by Stephani et. al. was done to find the results of full-spectrum lighting on the patron in a table service restaurant. The restaurant has two similar dining rooms. The lighting of the dining room was altered with a full-spectrum lamp to assess the behavior of patron but found no support for the hypothesis that patron would stay longer in the restaurant because of the change in lighting. The customers did not notice or comment on the new lighting and it had not affected the sales [9]. In the meanwhile, the researchers found that the sales were being affected by some factors other than food quality and light. The other step was to test the full spectrum light by other experiments.

A study was conducted to collect data available for restaurant management, services, facilities, and working techniques but did not find any information available on restaurant aesthetics. The research addressed the flows by monitoring the decoration of restaurants from a theoretical and economic perspective [14]. Age and competitive intensity were found as predictor variables affecting the decor of restaurants. The Ordinary Least Square (OLS) regression analysis of 243 Italian restaurants in Manhattan found that age and competitive intensity were negatively associated with decor competitive intensity. Flynn, a great researcher in the field of lighting assessment, developed criteria that are being used till now e.g. the criteria for lighting assessment in different rooms, he used subjective responses such as about balanced or unequal distribution of light, the brightness of the light, and about wall lighting [15]. He had used opposite remarks to check the responses of people about to analyze lighting such as pleasant or unpleasant, spacious or confined, clear or hazy [16].

Guenther and Zimmerman researched with an assumption that patrons select and prefer a particular restaurant because of its lighting, privacy, comfort, color, decor, architecture, and vegetation rather than the food menu, service, variety, prices of a restaurant. The questions discussed were about the aspects that brought the patrons to the restaurant and the restaurants that brought them back [17]. The two old average American restaurants, both serve Italian food with different location and atmosphere. The interior of the first restaurant was designed to give a feel of an Italian garden while eating and the second one with old timber and red bricks that dominated the space. Both restaurants had different interior philosophies but with somewhat similar ethnic attitudes. The data was collected through a questionnaire and its analysis showed that 50\% of the total sample considered lighting a considerable character in that domain patron of Vincenzo noticed the architecture but patron of Olive Garden had not given any attention to architecture, the reason could be that Vincenzo had a strongly built architecture rather than Olive Garden which had a typical gypsum wall and hidden with foliage. The color and decor had the same results which got average importance to the patron. The study got successful results for most of the assumptions for example patron in a restaurant considered architecture, interior, lighting, color, decor, and vegetation while selecting a restaurant.

The satisfaction of the consumer is a priority and then the business can be successful when that designed according to the requirement of its user. Patron satisfaction is also important to consider when a building is in use, no doubt that when a thing is used its drawbacks and benefits came to the front. The requirements of the users are drawn out from which a few would be achieved through renovation and alteration or a product could be better next time. The patron is responsible directly or indirectly for all the new styles, amendments, and inventions whether in light and color, or any other aspect of the building design, or the products. All business investors always need procedures and practices to increase their patron turnover rate [18].

The conclusion of all the above-mentioned studies gave a definite direction to the proposed research that the environment of the dining areas in the restaurant can be studied as a factor to affect the patron who comes there to dine in. The research paper is based on a case study, conducted to assess that how functionally and aesthetically, the light is used for the restaurant environment Secondly do functionally and aesthetically designed light and color affect the recreational aspect of restaurants. The research will open the new horizon in front of the interior designers 
and businessmen to design renovate or change the designs of the lighting in commercial places especially for the restaurants according to the need and demand of the place as well as according to the patron requirement [19]. That research will also give a direction to common persons as patrons that how to assess a place for its lighting quality where they are going to sit, stay, or buy. It is also related to the satisfaction that is to plan before implementation of a project in interior field [20].

\section{Research Methodology}

In this paper the qualitative and survey based research method has been used. The systematic literature review has been explored through internet and secondary data from published articles and research papers from relevant journals. The codes to evaluate the lighting were selected on the basis of Functional lighting and Aesthetical lighting. The qualitative study consisted of observations and interviews to gather data about the restaurant's lighting preferences. The method was divided into two parts:

1. Observation and recording of the interiors of the restaurant: In the first phase the entire restaurant was observed and all the detail of the interior was written down and photographs were taken for the record.

2. Interview Phase: Secondly the preliminary interviews were taken from the dinners to know their feeling and views about lighting in a restaurant. The owner and manager were interviewed to know the concept to design the interior of the restaurant and the deficiencies, they had noticed and the views of the patrons they heard about the light and color of the interior in the restaurant.

\section{Visual Survey of Interior Design of the Restaurant}

The restaurant was observed and the details were recorded for evaluation and final suggestions.

\subsection{Front Elevation}

The restaurant was situated in the basement of a building, named "The Planet". The name of the restaurant was written on the top of the front door which was "Premiere Family Dining" (Fig. 1).

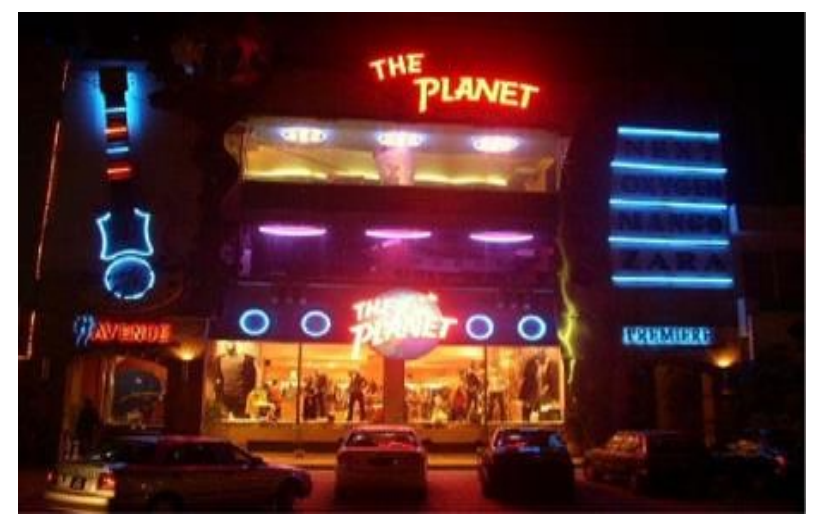

Figure 1. Front Elevation of the Restaurant

\subsection{Lighting}

\subsubsection{Ceiling Lighting}

Ceiling lights were playing the main role in creating an ambiance in the restaurant. The flat blue neon lights were mounted on the ceiling. They were installed in a row on the edges of the ceiling in the dining area of the restaurant (Fig. 2). Small round spot-lights were scattered to the equal distance on the whole ceiling, having a yellow color of the light (Fig. 2).

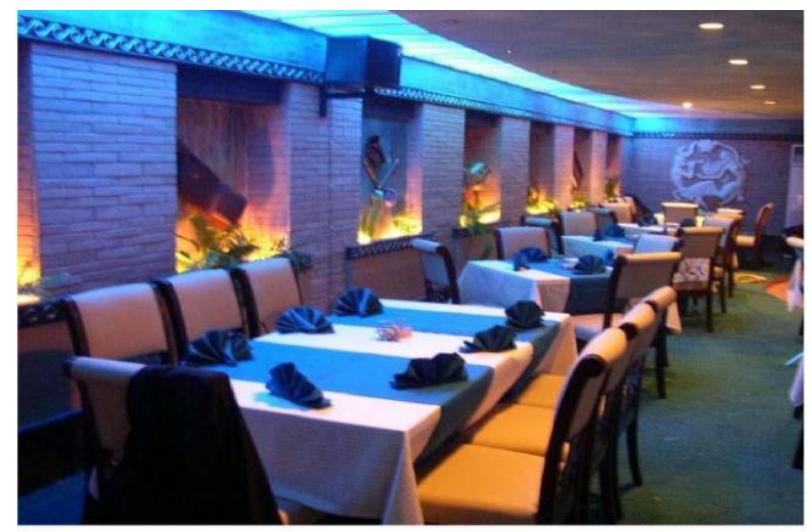

Figure 2. Blue-neon lighting in the Restaurant.

\subsubsection{Wall Lighting}

Before defining the wall lighting the buildup of the walls is important to mention. The walls were divided into sections by constructed deep depressions of four inches inside the walls; green shrubs along with musical instruments such as Sitar and Tabla were arranged as decorative features in each portion. The deep portions were highlighted with yellow halogen bulbs coming from under the shrubs (Fig. 2). 


\subsubsection{Columns Highlighted with Light}

Pillars were finished with the bricks of rust and beige colors and highlighted with white lighting on the top portion of the columns and lighting fixtures were mounted on almost two feet below the ceiling (Fig.3).

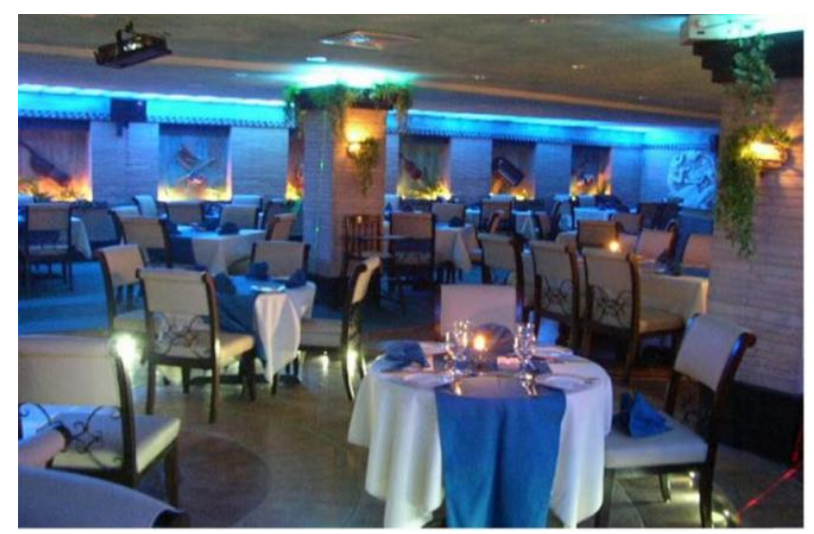

Figure 3. Up-lighting on Columns

\subsubsection{Screen Lighting}

A large screen of fiberglass with backlight and abstract motives in green colors displayed on a wall in the restaurant and a stage was made in front of the screen. The musical instruments were displayed on stage (Fig. 4).

\subsubsection{Multimedia Display Screen}

At the adjacent wall of the colored screen, a multimedia screen was mounted on the wall. The purpose of the screen was to show different videos for the entertainment to the patrons (Fig. 4).

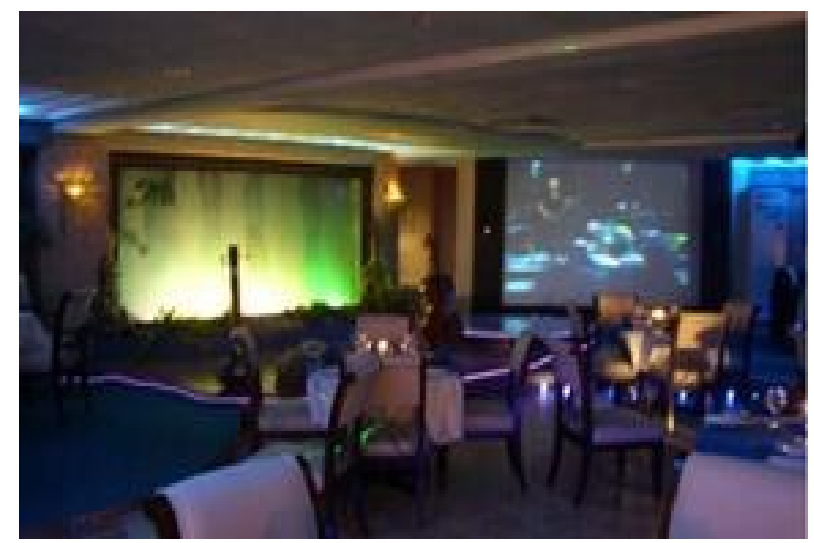

Figure 4. Multimedia Screen and Stage Screen

\subsubsection{Floor Lighting}

The floor was divided into different portions, one portion is covered with blue carpet and the other one was having tiles. In the center of the restaurant, a small portion of the floor was approximately six inches below from the rest of the floor in a circle. The selected area was highlighted by mounting lights on the edges of the circle (Fig. 5).

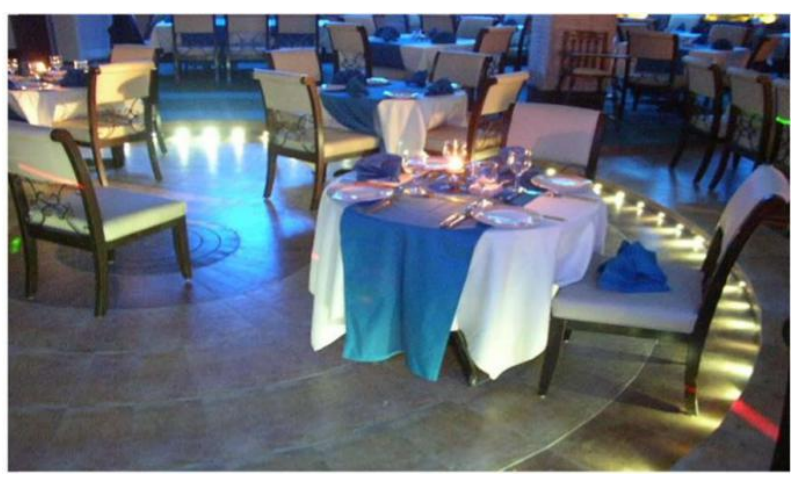

Figure 5. Floor Lighting in the dining area.

\subsection{Dining Area}

A small dining room was brightly lit with halogen yellow spotlights (Shown in figure 6) as a separate portion in the restaurant.

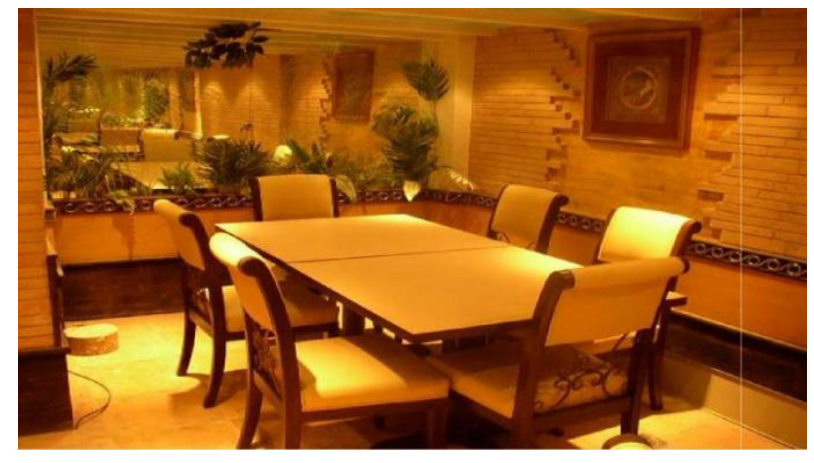

Figure 6. Small separate dining area.

\subsection{Color Scheme}

The chromatic color scheme is used where basic colors were neutrals, off white, beige and brown. The brown colour was widely used on walls, floor tiles and furniture, accompanied by blue color for ceiling lights and dining accessories e.g. napkins, etc. The floor carpet was also in blue, spread in the main dining area of the restaurant. The green color was also used to add up nature and variety to the interior of the dining.

\subsection{Furniture and Accessories}

The round and square tables were used with an arrangement of four or more, the white spreadsheets used as top covers with blue runners and napkins. The wooden chairs with white upholstery finish used with a grouping of four to six and more.

\section{The Interview Phase}

The interviews were directed from the owner of the restaurant and the manager to know their concepts and 
views to the selected design of the interiors and lighting. They were asked different questions related to lighting such as the restaurateur was asked questions in the following pattern:

1. Why have you started this business?

2. What is your ambition with its future?

3. Is it your passion or just a profession?

4. Who has designed the interior and lighting of the restaurant?

5. Are you satisfied with its interior and lighting design?

6. Which type of changes do you want in your restaurant lighting?

7. Do you want to know the views of dinners about restaurant lighting?

8. Would you accept suggestions about your restaurant lighting?

9. Do you have the patience to listen to the drawbacks of lighting in the restaurant?

The restaurant manager was selected for the study because of his direct interaction, dealing and relation with the dinners. The restaurant manager was asked different questions about lighting concerning dinners.

1. What are the comments of dinners about the lighting of the restaurant?

2. Have they ever mentioned that they come there because of lighting?

3. What do they demand lighting features?

Then both of them were also asked the questions planned for dinners. Then several dinners were selected for the interviews that come there regularly. The interviews were planned with the questions related to lighting attributes, used by Flynn [21]. The lighting features were used in many areas, so all those areas were discussed with interviewers. A list of attributes and questions is given below:

1. Why you select this restaurant for meals?

2. From how long you are coming here?

3. Have you ever noticed restaurant lighting?

4. Do you feel lighting is comfortable or not?

5. Is it bright or dim?

6. Is it pleasant or unpleasant?

7. Do you feel privacy in this place?

8. Is it spacious enough to enjoy here?

9. Do you feel relax or tense here?

10. Do you feel the provided light id clear or hazy?

11. What change do you want in the lighting of the restaurant?

The results were presented in two phases, in the first phase, the interviews were analyzed and in the second phase, the analytical suggestions were described to do alterations in the lighting of the restaurant.

\section{Analysis and Discussions}

The results were presented in two phases, in the first phase, the interviews were analyzed and in the second phase, the analytical suggestions were described to do alterations in the lighting of the restaurant. Those interviews had helped the researcher to conclude the results of doing alterations in the restaurant. That also helped to know the patron's demands about the light and color of the interior in the restaurant.

The owner said that his interior designer tried to provide maximum interest in the restaurant for the patron to become a regular customer. He gave more emphasis on different lighting, musical instruments, shrubs, wall screens, and running videos, since the restaurants are places which need attention towards aesthetics through lighting [1],[2],[5],[11]. Most of the interior options were selected by the owner himself, although the interior designer asked him to reduce the center of emphasis the owner said that he forced the interior designer to use all the emphasizing features which were present in the restaurant, the reason may be to attract more customers and to cater their different moods [5],[9]. The owner said that he knew now after the ten years of the restaurant setting, patrons are being attracted to the contemporary designed restaurants so he would do alterations in the interior of the restaurant, the reason can be that restaurants are the spaces that can impact on perceptions and emotions of their patrons so with the facilities and functionality alterations in settings can help [7],[8]. The manager said that although the regular customers did not want to change their restaurant place they suggested many times for the alterations in the interiors of the restaurant. The patrons liked the interior lighting but they want sharp and bright colors, even the light and color are present in numerous shades but consideration of the preferences is also important for the customer's gratification [1],[9]. They also commented on on-screen lighting and multimedia to have an entertaining feature while dining.

The researcher interviewed eight diners that came to the restaurant regularly. Most of the diners came there for food and also the environment of the restaurant. Even they were not very confined about lighting features or how to observe them but their answers gave a direction to the researcher. They all commented to alter the interior lighting with sharp neon and bright colors just like used in other new restaurants they visited. They considered lighting clear and pleasant and especially they feel privacy when dining there but wanted a more spacious and relaxing light. They also wanted dim lighting to add privacy and reduce glare, and restaurateur must focus on it because light can make a place depressing or enjoyable [12]. A research on full spectrum lighting in restaurant also concluded that it did not impact patrons [9] which can be gained with dim, relaxed and pleasant light [1],[18],[20].

The respondent felt that lighting was more aesthetical and wanted to make it more functional by reducing the light intensity and shades of light. The results showed that the restaurant was chosen because of its hospitality, food 
taste, and family environment but the aesthetical layout cannot be ignored because of financial stress [14]. The dinners were not very interested in lighting because they lacked the knowledge but they show interest in colors according to their knowledge and skill. Then they were given some instructions and knowledge about the light and color by the researcher herself and then they again asked the questions to get some authentic data about the lighting and it is frequent that people do not consider lighting as important as other elements of interior and they have no formal or informal knowledge about it in Pakistan. The study can have a dimension like Flynn to use checklist of opposite attributes to analyze lighting such as pleasant or unpleasant, spacious or confined, clear or hazy [15],[16],[21] instead of asking statements. In many previous research, it was found that customers select restaurants not only because of food but they have sensibility for architecture, interior, lighting, color, decor, and vegetation while selecting a restaurant [17]. The dinners were unaware of the technical and aesthetical requirements of the lighting in a restaurant but, unconsciously, they gave good comments about creating an ambiance through light. The patrons were inspired by the decorative screen and projector screen (Fig. 4) which was a unique idea in the restaurant.

\section{Conclusions and Recommendations}

The research shows that the lighting of the restaurant is used excessively for aesthetical purposes such as light coming from the ceiling, walls, pillars, floor but with no control of voltage or intensity of light. The excessive use of light increases the expenses on electricity and creates blurriness. The lighting design needs a few alterations to bring the restaurant up to date and more functional than it is. The intensity of lights must be lowered down to create a more effective ambiance. The tables must be spot lit to avail the light for proper illuminance and brightness on food. These alterations did not require much of finance but they would bring a blooming change in the interiors of the restaurant.

It was a family restaurant as visible by its name "Premiere Family Dining" and its interior was relaxing, welcoming, and enjoyable but there were some deficiencies that could be changed only by doing small changes and alterations. The following recommendations should be incorporated while designing the lighting of the restaurants:

1. To highlight the entrance of the restaurant, the decorative lights can be arranged on the edges of the entrance, because the restaurant was situated in the basement and its entrance door was on the ground floor which only had its name written with neon lights (Fig.1). The furniture and all other accessories were common but durable in design and that was a good effort to have the basic things for longer usage.
2. The use of blue lighting must be reduced because of its dull impact on diners' faces (Fig. 2). The other option was to reduce the intensity of the ceiling lights.

3. The blue lights were directly coming down on the dining tables arranged near the edges of the walls which affected the color of the food (Fig. 2).

4. The spotlights on the ceiling were not fulfilling their purpose because dining tables need to be arranged exactly under the lights to enhance food (Fig. 2) and also necessary to read the menu and to look at each other. The same problem was coming in the small dining area (Fig. 6) which also needs correction of the placement of the spotlights.

5. The top portion of the columns in the hall was also highlighted through lighting (Fig. 3) and plants on the top edges with the ceiling but that was over lighted, the intensity of the lights must be reduced.

6. The decoration on walls looked in excess (Fig. 2), only the lights of low intensity and shrubs were enough. The musical instruments could be placed but not in every depression in the wall.

7. Floor lights should be of low intensity because of the glare coming in the eyes of the viewer (Fig. 5).

8. The multimedia screen and stage screen must be placed on opposite walls of the restaurant than adjacent screens, to create one focus of interest on one wall (Fig. 4).

9. For future researchers, a checklist of opposite attributes can be used to analyze lighting such as pleasant or unpleasant, spacious or confined, clear or hazy like Flynn had used first and other researchers opted from him [16],[20].

The interior of the restaurant was giving relaxing, cool, and calm effects. The color and light combination created an effect of simplicity by using white, beige, and blue color.

\section{Acknowledgements}

The authors are thankful to the owner of the restaurant for the help and cooperation to use the restaurant for the research study.

\section{REFERENCES}

[1] S. Farooq, M. Khan, A. Ahmed. Employees Comfort Level in Existing Lighting at Arfa Software Technology Park: A Case Study. Science International. Lahore, Vol. 31, No. 5, 785-788. 2019..

[2] D. Philips. Lighting in Architectural Design. New York: McGraw- Hill. New York, USA, 1964.

[3] K. Ryu. Dinescape, Emotions and Behavioral Intentions in 
Upscale Restaurants, Unpublished ph. D. Thesis, Dept. of Hospitality Management, Kansas State University, USA. 2005.

[4] O. N. Eisazadeh, K. Allacker, \& F. De Troyer. The Impact of Window Systems on Daylighting Performance, Visual Comfort, and Energy Efficiency In-Patient Rooms. Proceedings of the International Building Performance Simulation Association”. 2019

[5] F. Knapp. Hotel Renovation Planning and Design, New York: McGraw-Hill. 1995.

[6] J. S. Horng, S. F. Chou, C. H. Liu, \& C. Y. Tsai. Creativity, aesthetics and eco-friendliness: A physical dining environment design synthetic assessment model of innovative restaurants. Tourism Management, 36, 15-25. 2013.

[7] K. Ryu, \& S. S. Jang. The effect of environmental perceptions on behavioral intentions through emotions: The case of upscale restaurants. Journal of Hospitality \& Tourism Research, 31(1), 56-72. 2007.

[8] V. C. Heung, \& T. Gu. Influence of restaurant atmospherics on patron satisfaction and behavioral intentions. International Journal of Hospitality Management, 31(4), 1167-1177. 2012.

[9] A. R. Ningrum. Interior Design Forms of Njah Djambon Restaurant In Surakarta Based On Aesthetic Perspective. 2020.

[10] A. Gill. Developing a Business Plan Across Culture. Unpublished Master's Thesis. University of Applied Sciences, Stockholm, Sweden, 2011.

[11] A. E. Ciani. A study of how lighting can affect a guest's dining experience. Graduate Thesis and Dissertation. Digital Repository, Iowa State University. 2010.

[12] H. Southern. University student's perceptions of lighting and preferences for the setting and social arrangements in contrasting dining. Unpublished Master thesis. The University of Florida. 2005.

[13] K. A. Stephani, Robson, E. Sheryl, \& Kimes. Effects of Full Spectrum Light. Cornell Hospitality Report, Vol. 7, No. 12, 2007.

[14] N. Rehman. Toward a theory of restaurant Décor: An empirical examination of Italian restaurants in Manhattan. Journal of Hospitality \& Tourism Research, Vol 34, No. 3, 330-340. 2010.

[15] J. E. Flynn. Concepts beyond the I.E.s framework. Lighting Design and applications, Vol. 1, No. 3, 4-11, 1973.

[16] J. E. Flynn, C. Hendrick, T. Spencer \& O. Martyniuk..A guide to methodology procedures for measuring subjective impressions in lighting. Journal of Illuminating Engineering Society, Vol. 8, 95-110, 1979.

[17] J. Guenther, B. Zimmerman. (2005) Restaurant Research. Online available from http:/www.architecture.unl.edu/proje cts/bsfed/projects/restaurants_research.pdf

[18] S. Ayaz. Comparison of Two Aesthetical Lighting Plans in Moderate Upscale Restaurants on Patron Turnover Rate (PTOR). Science Int., Lahore, Vol. 27, No. 4, 3575-3578, 2015.

[19] R. Arora J. Singer. Cognitive and affective service marketing strategies for fine dining restaurant managers. Journal of Small Business Strategy Vol. 17, 51-61, 2006.

[20] S. Farooq. Impact of Ambience on Dinners' Satisfaction in Food Street Restaurants: A Widening Horizon in the World. Orient Research Journal of Social Sciences. ISSN Print 2616-7085 ISSN Online 2616-7093. Vol.4, No. 2. 229-240. December 2019 .

[21] J. E. Flynn. A study of subjective responses to low energy and non-uniform lighting systems. Lighting Design and Application, Vol. 7, No. 2, pp. 6-15, 1977. 